Marcelo Rosanova Ferraro'

Universidade de São Paulo, São

Paulo - SP, Brasil

e-mail: marcelo.rosanova.ferraro@ usp.br

DOI

http://dx.doi.org/10.1590/2236-463320151016
BEATTIE, Peter M.

Punishment in Paradise: Race, Slavery, Human Rights, and a NineteenthCentury Brazilian Penal Colony.

Durham / London: Duke University Press, 2015, 337p.

\section{Fernando de Noronha e o Mundo: A Colônia Penal do Império em Perspectiva Atlântica no Século XIX}

Publicada em 2015 por Peter M. Beattie, professor da Universidade de Michigan, a obra "Punishment in Paradise: Race, Slavery, Human Rights, and a Nineteenth-Century Brazilian Penal Colony" consiste em um ambicioso estudo de caso, em que a colônia penal de Fernando de Noronha se converte em um microcosmo para a análise de temas como raça, cor, escravidão, gênero, sexualidade, punição, justiça e direitos humanos, tanto em relação à sociedade e ao Estado brasileiros quanto ao quadro atlântico ou global.

Em primeiro lugar, o autor possui o mérito de escapar das armadilhas teóricas e metodológicas de estudos sobre prisões e punições, evitando a mera reprodução ou negação do paradigma foucaultiano ("Vigiar e Punir: 0 Nascimento da Prisão"). Tampouco recai nas versões simplificadas do debate sobre "ideias fora de lugar" ou no reducionismo binário de categorias como arcaico e moderno, afastando-se de alguns dos vícios que acometem obras de referência sobre o tema na América Latina e no Brasil. A partir de uma apropriação muito particular dos estudos e aportes teóricos e conceituais de Erving Goffman, Lewis Coser e David Garland, Beattie esboça uma criativa analise em que a ilha, o Império do Brasil e o Atlântico (quiçá o globo) se cruzam em múltiplas escalas geográficas, sociais e discursivas do oitocentos.

Os primeiros capitulos perpassam a historia da ilha desde a colonização portuguesa até o século XIX, com sua progressiva conversão na principal colônia penal do Estado brasileiro. 0 autor descreve o cenário e os atores envolvidos sem perder de vista o quadro mais amplo da sociedade brasileira e do Estado e suas instituições em formação, dando-se a um luxo do qual não usufruíam os condenados em seu isolamento, em que remetiam à sua ilha como "Fernando" em oposição ao "mundo" (continente). Fernando de Noronha adquire ao longo do texto tanto a condição de espaço físico, geográfico e social quanto a de representação compartilhada e disputada pelos agentes históricos, ora como cenário idílico ora como cárcere. Assim como a escravidão, a ilha se converteu em metáfora nas representações sobre liberdade e sua negação, servindo aos mais variados discursos e interesses.

Muito transparente em relação à metodologia adotada e à documentação analisada, Beattie apresenta as contradições entre o caráter normativo dos discursos de autoridades da alta burocracia imperial, da legislação vigente e dos regimentos oficiais e a realidade cotidiana da ilha, em que militares e condenados de diversas cores e condições civis (inclusive escravos) reinventaram suas vidas e identidades. Enquanto os discursos penais da primeira metade do século XIX remetiam a um estrito controle do tempo e do espaço, a arquitetura e a rotina da colônia possuiam condições muito particulares, não decorrentes de um caráter arcaico da sociedade escravista e das instituições brasileiras, mas em parte pela própria condição geográfica insular e pelas relações sociais muito particulares desse micro-
Bolsista de Mestrado da Fundação de Amparo à Pesquisa do Estado de São Paulo (FAPESP). 
cosmo social. Por entre as brechas do sistema, pessoas livres conviviam com condenados, e formas de comércio e de contrabando se misturavam à rotina imposta pelos regimentos. Contudo, esse submundo de Fernando de Noronha não é tomado como a negação de sua função, mas como a face complementar ("dark twin") típica de todo ambiente penal planejado, sendo inclusive incorporado e defendido nos discursos dos administradores.

Ao abordar o trabalho dos presos nos campos agrícolas e outras atividades, 0 autor apresenta um interessante paralelo entre prisão e plantation, resvalando em uma tradição de estudos de cunho marxista que relacionam a esfera da produção e as práticas punitivas (Georg Rusche e Otto Kirchheimer, "Punishment and Social Structure"; Dario Melossi e Mario Pavarini, "The Prison and the Factory"). No entanto, as aproximações sugeridas por Beattie não se pautam pela dimensão econômica, especialmente tendo em vista o caráter deficitário da produção da colônia - em oposição à alta lucratividade de grande parte das plantations do continente - e o fato de que a maioria dos condenados não retornaria à sociedade na condição de mão-de-obra disponível. Amparado nas reflexões de David Garland, Beattie adota uma abordagem pluralista e multidimensional da punição, sem recair nas fórmulas do marxismo, do paradigma foucaultiano ou do simbólico durkheimniano, mas buscando combinar esses referenciais clássi$\cos$ da sociologia da punição. É o caráter de instituições disciplinares que faz convergirem os ambientes e as práticas da colônia penal, das fazendas escravistas e até mesmo de agrupamentos militares.

Ao dialogar com outras duas referências do campo da sociologia, Erving Goffman e Lewis Coser, o autor apresenta uma das contribuições mais originais da obra no quinto capítulo. Por meio do uso alargado dos conceitos "instituição total" e "instituição gananciosa" ("greedy institution"), Beattie contradiz a suposta tensão entre a instituição da família e outras instituições disciplinares nas práticas narradas em Fernando de Noronha. Na gestão da colônia penal as autoridades passaram a questionar as diretrizes normativas referentes a gênero e sexualidade - isolamento e abstinência dos condenados -, defendendo a presença de mulheres e a constituição de laços familiares heterossexuais. 0 casamento se converteria em política abertamente defendida pelas autoridades da ilha, como instituição voltada à disciplina e à produtividade dos condenados: a "instituição ciumenta da conjugalidade heterossexual" ("jealous institution of heterossexual conjugality").

Outra importante contribuição decorre da análise dos conflitos entre os militares que geriam a colônia penal e as autoridades da alta burocracia estatal, em geral pressionados pelos interesses de proprietários de escravos. Desde os primeiros capitulos o autor demonstra a politização das questões penais e prisionais no processo de formação do Estado. É evidente ainda o papel da política partidária no que se refere a nomeações de cargos e práticas clientelistas, que atrelavam a gestão da ilha ao jogo político do continente. Na segunda metade do século XIX, diante dos sucessivos embates sobre a escravidão e as constantes comutações de penas de morte pela ação do poder moderador, a colônia penal de Fernando de Noronha se converteu em uma representação disputada pelos agentes sociais. Curiosamente, tanto abolicionistas como defensores da manutenção da escravidão faziam uso da comparação entre a condição prisional e a escravidão no mesmo sentido, apontando a segunda como pior que a primeira. Entretanto, enquanto abolicionistas questionavam o cativeiro como indigno e pior 
que a prisão, escravocratas criticavam as comutações de penas de morte em galés ou prisão, sugerindo o risco de se incentivar a criminalidade dos escravos que prefeririam correntes e grades às senzalas. Nesse discurso, a colônia penal se tornava a ilha do rei, onde os escravos se livrariam do cativeiro. Como insiste 0 autor, tal percepção não correspondia à realidade dos números dos crimes e de escravos em Fernando de Noronha, o que, todavia, não invalida a importância de sua representação no imaginário oitocentista.

Nesse contexto, as autoridades locais passaram a ser questionadas por membros da alta burocracia sobre as praticas de gestão da llha, especialmente a partir da década de 1880, com a visita de inspetores nomeados pelo Ministério da Justiça. Entre as principais divergências estavam a própria política de promoção de casamentos ("jealous institution"), o reduzido controle do tempo e do espaço de circulação dos condenados, a quantidade de trabalho imposto e a falta de segregação e hierarquização da população prisional com base na condição civil. Quanto último quesito, as autoridades respondiam aos anseios de uma sociedade que ainda legitimava a escravidão e aos interesses de proprietários que se sentiam ameaçados pela crescente rebeldia de seus cativos e pela ascensão do movimento abolicionista. Entretanto, administradores da colônia se negavam a adotar uma gestão que segregasse e punisse de forma diferenciada escravos ou libertos. Esse dado permite ao autor sugerir uma estratificação menos clara entre os condenados das mais diversas cores e condições civis, aglomerados na categoria dos pobres intratáveis ("intractable poor"), pois, na colônia penal, condenados que fossem escravos ou livres compartilhariam de condições de vida e oportunidades muito semelhantes. 0 autor é cauteloso e nega qualquer subsídio à ideia de uma democracia de condição civil ou racial nas prisões, argumentando apenas contra estudos que avaliaram a condição de escravos nas prisões a partir da legislação e regulamentos.

0 capitulo que antecede a conclusão, intitulado "Direitos Humanos em Perspectiva Atlântica" ("Human Rights in Atlantic Perspective") destoa em forma e conteúdo do restante do livro. No entanto, se a escolha aparentemente rompe a harmonia do texto, a reflexão de cunho ensaístico e as hipóteses levantadas conferem maior profundidade e relevância à obra. A proposta comparativa tem por foco principal Brasil e Estados Unidos no século XIX, mas inclui outros espaços do globo, inclusive para além do Atlântico. Entre os pontos levantados, dois merecem destaque. Em primeiro lugar, o autor aponta o paradoxo de o Brasil, último país a abolir a escravidão, ter sido um dos primeiros a abolir de facto a pena de morte. Esse fenômeno negligenciado pelos que estudam o tema contradiz argumentos da historiografia sobre os Estados Unidos que defendem a relação intrínseca entre pena de morte e escravidão para justificar as divergências regionais do judiciário no país. Ainda nesse quesito, o autor se une aqueles que defendem a importância da atuação de D. Pedro II na política nacional, especialmente no que se refere ao judiciário, pois se a abolição da escravidão era um tema essencialmente do Legislativo, as prerrogativas do poder Moderador lhe permitiram atuar para por fim às execuções de penas capitais, inclusive no sentido de defender internacionalmente a imagem do país.

Em segundo lugar, Beattie sustenta a hipótese de que reformas referentes às penas corporais, à pena de morte e à escravidão se cruzaram e se estimularam mutuamente, e que aquelas que se referiam a melhorias no tratamento de algumas categorias sociais abriam possibilidades para futuras reformas referentes aos grupos ainda marginalizados. A título de 
exemplo, reformas contra penas corporais a homens livres teriam aberto a possibilidade de debates acerca das condições de prisioneiros e, inclusive, escravos. Além do mais, como se referiam a diferentes integrantes dos grupos marginalizados da sociedade, a hipótese de reformas graduais é utilizada pelo autor para defender a categoria relativamente indiferenciada dos "pobres intratáveis" ("intractable poor").

Por fim, o trabalho margeia o anacronismo ao se escorar no conceito de direitos humanos para retratar o fim do século XIX, sem, contudo, comprometer seus argumentos centrais. Diante da tendência de estudos sobre escravidão e raça se valerem de tal discurso, esse pecado dos historiadores pode se converter em virtude no que se refere ao posicionamento político no presente em que a obra se insere.

A partir de um estudo de caso original e ambicioso, Peter Beattie apresenta uma obra de múltiplas escalas, descrevendo as minucias do cotidiano desse microcosmo, perpassando o imaginário e os discursos da sociedade oitocentista brasileira, e utilizando de forma criativa modelos clássicos da sociologia. Um dos pontos altos do estudo, o voo panorâmico atlântico esboçado nos últimos capítulos apresenta uma promissora proposta de história comparada, que se levada adiante trará grandes contribuições para historiografia. Ainda que Brasil (ou o Atlântico) não caiba em Fernando de Noronha, Beattie faz dessa colônia penal uma janela para muitas dimensões do século XIX. 